\title{
With this year's close, the end of an era
}

\author{
David H Henry, MD, FACP
}

T

This is the final issue of The Journal of Community and Supportive Oncology. Since our launch - separately as the Journal of Supportive Oncology in 2003 and Community Oncology in 2004 - and through the 2014 merger to form JCSO, our purpose has always been to connect with practicebased caregivers and to provide them with carefully selected, peer-reviewed information that could easily be incorporated into daily practice. Our overarching goal was to help ensure the delivery of the best-possible care and outcomes for our patients. We hope we achieved that, and the results of a 2016 readership survey seemed to confirm as much. But from a business perspective, and especially with the transition to online publishing and intensely competitive advertising landscape, economic survival became increasingly elusive, and management decided to close the journal.

JCSO was one of the few publications to span clinical and supportive care and to reach out to the entire oncology care team - oncologists, supportive care specialists, advanced practice providers, and pharmacists. Patients - their needs, concerns, and well-being - were always at the forefront of our thinking when we planned our issues. In the 2016 survey, our readers told us that they read the journal mainly to learn about clinical and supportive developments $(72 \%$ and $57 \%$ of respondents, respectively), and almost $60 \%$ indicated that they routinely used information presented in our articles in their practice. To achieve those goals, we drew on the expertise and steady guidance of many over the course of our lifetime and we owe a deep gratitude to our editors emeriti, Lee Schwartzberg, MD, (Community Oncology) and Michael Fisch, MD, and Jamie von Roenn, MD (JSO), as well as the associate editors, members of the editorial advisory board, reviewers, authors, and of course, you, the reader.

I'd like specifically to thank the incumbent editors, Jame Abraham, MD; Howard Burris, MD; David Cella, PhD; Kevin Knopf, MD; and Thomas Strouse, MD for their support and invaluable contributions in recent years. Thank you too, to past associate editors Linda Bosserman, MD, (Community Oncology, JCSO; 2004-2018); Debra Patt, MD (Community Oncology, JCSO; 2012-2016); and
Debra Barton, PhD (JSO, 2003-2013). And a special word of thanks to Jane de Lartigue, $\mathrm{PhD}$, whose in-depth New Therapies articles and Community Translations reports helped describe and explain the science behind the therapies we use daily.

pies we use daily.

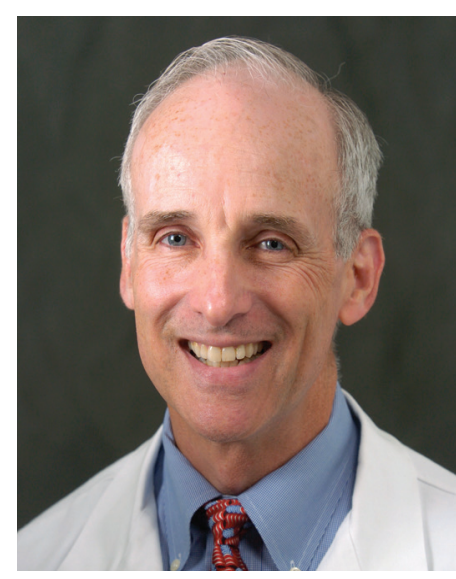

\section{Looking ahead}

From January 2019, JCSO's sister publications, Hematology News and Oncology Practice, will reside on a shared digital platform, MDedge Oncology, that will focus on news and conference coverage. Archives for JCSO, JSO, and Community Oncology will be available on this new platform at www.mdedge.com/oncology after the launch. In addition, I will host a weekly podcast focusing on current trends and advances in clinical and supportive care. It will include a long-form interview with an expert in oncology, along the lines of the former JCSO Interview, and with short endsegments on patient care, translating new research to daily practice, and a monthly journal round-up. You'll be able to subscribe to and download it at Apple podcasts, using the search terms Hem Onc and MDedge.

\section{In this issue}

We end with a bumper crop of articles, beginning with a report by Hedden and colleagues on page e234 describing how they developed, implemented, and evaluated a supportive care program for patients with prostate cancer. That is followed by a literature-based review article by Ibrahim colleagues detailing the effectiveness of duloxetine in the treatment of painful chemotherapy-induced peripheral neuropathy (p. e243). In the original research section, on page e250, Palmisiano and colleagues report on mortality outcomes in hospitalized patients with cancer after rapid response team activation; Jeurkar and colleagues compare risk models guiding growth factor use in chemotherapy (p. e256); and Chao and colleagues describe the symptom burdens associated with chemotherapy-induced anemia in patients with late-stage cancer (e260).

Challenging and elusive are the key words in this issue's Case Reports in which Pollock and colleagues describe the difficulties in managing a cetuximab rash (p. e272), Roberts and colleagues write about elevated liver function tests in a patient on palbociclib and fulvestrant (p. e277), and

JCSO 2018;16(6):e226-e227. (02018 Frontline Medical Communications. doi: https://doi.org/10.12788/jcso.0433 
Mukherjee and colleagues describe a patient with intravascular large B-cell lymphoma, who presented both a diagnostic and management challenge for the care team (p. e280). Turn to page e283, where our regular contributor, Jane de Lartigue, has written an in-depth review on everything you need to know about biosimilars. Susan London follows up on page e290 with an article on findings from studies on biosimilars for 3 oncology drugs that were reported at this year's annual meeting of the American Society of Clinical
Oncology. Dr de Lartigue also reports on the approval of dabrafenib and trametinib for BRAF-mutant melanoma (e228) and osimertinib for advanced non-small-cell lung cancer (p. e231).

\section{And finally...}

I wish you and your colleagues and families all good things for the coming year. Thank you and goodbye - and stay in touch by downloading my podcast! 